\section{The everyday life of a diabetic child in Estonia}

Sir,

In Estonia, ten years ago, an average of 30 to 40 children per year became ill, and now the number has increased to 60 to 80 . There are already more than half a thousand diabetic children over the age of $15,^{[1]}$ in Estonia.

To get an accurate overview of the way Estonian families cope with type 1 diabetes, Estonian Children's and Youth Diabetes Association (ELDÜ), with the help of the NGO Fund of the Open Estonia Foundation, carried out a study on the health and quality of the life of children and youth with diabetes and their families, ${ }^{[2]}$ during the period from February to March 2010. What do children with diabetes think about their disease and the limitations it sets on their everyday lives?

Seventy three children and young people aged 7 to 19 years filled out a special questionnaire for children/youth, which covered a total of 78 statements and questions. Thirty-eight children of the 73 had been hospitalized in the past year (including one child who was hospitalized 5 to 6 times and another more than 10 times). Although half of the children said that their family doctor advises them sufficiently about diabetes, the other half responded negatively. Majority are satisfied with the availability of specialized medical care provided for diabetes (94 percent).

The survey uncovered the problems the children encountered with diabetes. The study stated that 26 percent of kindergarten-aged children were domestic, because kindergartens refused to accept these children due to their illness. This means that one of the parents had to stay home with the child. Fifty-seven percent of the children with diabetes were able to attend kindergarten; however, their parents had to come several times a day to measure their blood sugar levels and administer insulin, as the kindergarten staffs refused to perform these activities.

According to the same survey, about 22 percent of children required the help of an adult, mainly in primary school. Only half of them were assisted by someone from the school staff, the rest received help from the parent or an older sibling studying in the same school. Seventy eight percent of the schoolchildren, due to circumstances, are able to manage their diabetes themselves, but such a responsibility is not age-appropriate and warrantable. When all the responsibility lies on the child, in due course the chances that the exhausted child comes home from school with high blood sugar levels and headache. Alternatively, the low blood sugar with all its symptoms may endanger the child.

An aim of the study was to clarify whether the children suffer from unequal treatment due to their diabetes. Unfortunately, there are still cases in which a diabetic child will not be brought along to a class trip, on a hike with peers or to another event. It is good to know that for most children claim that they have never been bullied due to diabetes. Sixty-five percent of the interviewed children claimed this as the case; however, at the same time, it has happened sometimes for 8 percent of the interviewed children and often for 5 percent. Furthermore, every other child has never felt embarrassed because of his/her illness.

It can be claimed that many children are concerned about subsequent complications ( 30 percent of the children worried about complications almost always, 35 percent often and 21 percent sometimes).

Sixteen percent of the parents said that their child's diabetes has often affected their sleep schedule and 25 percent responded that it affects their sleep schedule almost always. On average, parents wake up 1 to 2 times per night, 6 times at most.

To what extent have children with diabetes been able to engage in their favorite activity? 67 percent claimed that they have not had to give up anything, however, every third child responded affirmatively. Activities such as volleyball, tennis, dancing, swimming, skiing and orientating were highlighted, along with the fact that one cannot go to the movies or to town with friends, to camp, take long field trips; some children said they had to give up on attending a friend's birthday due to of their diet, injections, etc. At the same time, doctors emphasize that physical activity and sports are a part of the treatment of diabetes. While physical activities are a necessity, professional sports must be avoided.

The children said that low blood sugar levels make them feel weak and incapable of doing anything; they cannot focus, they are dizzy and weak, their vision is blurred and double vision occurs; trembling hands hamper writing; it causes tachycardia; and the children feel angry at the entire world. The children said that high blood sugar levels make 
their mouth dry and make them thirsty; they feel irritable and easily angered; they have headaches and hard to focus; they are tired and they suffer from sleeping disorders; it makes them urinating often; their vision is cluttered.

Do the children speak openly about their diabetes? 37 percent claim that they never have, 15 percent have done it often and 7 percent have almost always done it.

What do the children think all people should know about diabetes? The general consensus is that all people should know what kind of disease diabetes is and how one can help a diabetic in need; that diabetes is an incurable illness which can be managed; that diabetes is not contagious; that it can happen to anyone; that a diabetic is not a drug addict.

Majority (62 percent) of the children do not see anything good in diabetes. A closer look revealed that the following was seen as a positive side of it: Broadened insight and knowledge about health the children take better care of their health than they would otherwise; the children have adopted a healthy diet ("I have learned to eat more vegetables, which is very good, as one cannot eat candy indefinitely"); it makes them think about the future; diabetics become more orderly.

The aforementioned project also focused on particular suggestions on ways to help a diabetic child who is attending school or kindergarten for the first time or who is switching educational institutions.

Specially trained diabetes nurses visit the educational institution three times, to train the staff of the institution. Instructional materials on children's diabetes have been developed for the training, which are freely available for the staff of the educational institution. The board of the school or the kindergarten appoints individuals who, on the basis of the needs of the child in question, are given specific instructions on how often, at which times or in which cases a need to check the child's blood sugar is required.

The instructions for the kindergarten or school include the exact insulin dosage to be administered with an injection or pump to a particular child, as well as the order of administration. In regard to food, it is noted, whether the child needs to eat at a particular time and whether it should contain a certain amount of carbohydrates. In addition, the instructions note the type of the blood glucose meter used and the appropriate syringes and pumps for the treatment. Instructions on how to operate in case of low blood sugar will be provided for any particular child.
Further success depends on the good cooperation between the staff of the educational institution, parents and diabetes medical personnel.

Virve-Ines Laidmäe

Researcher, Institute of Social Work, Tallinn University, Estonia

Corresponding Author:

Mrs. Virve-Ines Laidmäe, Researcher, Tallinn University, Estonia. E-mail:Virve.laidmae@gmail.com

\section{REFERENCES}

1. Estonian children become more and more diabetic. Estonian Doctor homepage: Available from: https://www.arst.ee/et/ Uudised-ja-artiklid [Last accessed on 2013 Mar 12].

2. PedsQL $L^{\mathrm{TM}}+$ the ELDÜ study in 2010. (ELDÜ - Estonian Diabetes Association for Children and Youth) The survey is a part of the ELDÜ 2010 project "Parem elukvaliteet ja võrdsemadvõimalused diabeedihaigetele lastele ja noortele" [Better quality of life and equal opportunities for children and young people with diabetes]. The project is financed by the fund, which is financed by Norway, Iceland and Liechtenstein through the Open Estonia Foundation. Available: http://lastediabeet.ee/wp-content/uploads/2010/05/ uuring-2010-tutvustus-aprilll-kodulehele1.pdf [Last accessed on 2014 February 7].

\begin{tabular}{|l|l|}
\hline \multicolumn{2}{|c|}{ Access this article online } \\
\hline Quick Response Code: & Website: \\
\hline & www.josh.net \\
\hline & \\
\hline
\end{tabular}

